\title{
Território e territorialidade no Império Romano: a utilização do padrão urbanístico das cidades construídas enquanto tática de romanização
}

\author{
João Carlos de Mattos Freitas \\ Professor de Geografia do Instituto Elo de Educação \\ Formado em licenciatura plena pela UERJ-FFP
}

\section{Resumo}

Roma foi uma cidade que expandiu seu poder ao ponto de se tornar um grande Império, com sua territorialidade presente por séculos em boa parte da Europa Ocidental, além do norte da África e parte da Ásia. Suas táticas de territorialização iam desde o inicial domínio militar até a utilização das políticas de romanização, onde incluímos a introdução dos costumes romanos como a religião, as tradições, numa clara tentativa de transformação dos povos sob o domínio de Roma em romanos. Entre essas táticas existentes destacamos em nossos estudos a padronização da arquitetura e o planejamento urbanístico das cidades construídas ou reconstruídas por Roma. Dessa forma, pretendemos ao final do artigo propor uma análise geohistórica do Império Romano, na tentativa de contribuir para um maior dialogo entre a História e a Geografia.

Palavras-chave: território; territorialidade; Império Romano; romanização; política de conquistas.

\section{Abstract}

Rome was one city that expanded its power becoming a big Empire, with its territoriality present during centuries in one big part of the Occidental Europe, but also in the North of Africa and one part of Asia. Rome tactics of territoriality include the first military dominion and the use of the politics of Romanization involving the introduction of the Roman habits as: religion, the traditions, in a real try of transforming the people under the rule of Rome in Romans. Among these tactics we can emphasize in our studies the standardization of the architecture and the urban planning of the cities built or rebuilt by Rome. So, at the end of this article, we intend to propose a geohistoric analysis of the Roman Empire trying to minister a bigger discussion between History and Geography.

Key Words: territory; territoriality; Roman Empire; romanization; politics of conquest. 
A Geografia enquanto ciência busca entender os processos de produção do espaço humano. Para tanto ela necessita dialogar com diversas áreas do conhecimento, buscando um olhar sobre a totalidade dos elementos que compõem e influenciam o espaço. É dessa forma que percebemos ao longo da história do pensamento geográfico, correntes que serão influenciadas por áreas como a História, a Geologia, a Sociologia, entre outras.

Dentre essas, a História possui um papel fundamental para o desenvolvimento da Geografia, visto que não podemos compreender as condições essenciais para a produção do espaço sem incluirmos os processos históricos. Contudo é notório perceber que esse diálogo é pouco explorado nos meios acadêmicos da atualidade.

Pretendemos nesse artigo propor um diálogo entre as ciências histórica e geográfica - em uma análise geohistórica do objeto empírico - onde buscaremos focar nossos estudos no planejamento urbanístico padronizado das cidades conquistadas e fundadas por Roma, entendendo-a enquanto tática de romanização implementada aos povos conquistados.

Consideramos como política de conquista toda ação romana utilizada para o fim de dominar e consolidar suas conquistas. Nesse caso acreditamos que Roma revolucionou essa estratégia, impondo seu estilo de vida a partir do planejamento urbano, dos monumentos, dos cultos, entre outras táticas, a todas as cidades conquistadas, ao mesmo tempo em que tentavam ser complacentes com a cultura dos povos, caso não atrapalhasse a "legitimidade" de seu domínio.

Os períodos iniciais de Roma (entre os séculos VIII a.C. e III a.C.) tiveram um caráter muito mais defensivo do que expansionista. Essa postura mudou com o decorrer da história para uma estratégia ofensiva aos povos que ameaçavam sua soberania, pois além de desestruturar o poder militar de seus inimigos, Roma obtinha muitos lucros oriundos dos espólios das guerras vencidas. "Os soldados e os chefes tinham experimentado a pilhagem, a embriaguez do poder e, progressivamente, os espíritos começaram a imaginar a possibilidade de novas conquistas (GRIMAL, 1984:45)". Todavia ela só conseguiria de fato manter uma constância de conquistas após as Guerras Púnicas ${ }^{1}$, onde passou a ser a principal potência comercial do Ocidente, fazendo com que Roma pudesse exercer seu domínio militar, político e econômico. O controle do comércio do Mediterrâneo possibilitou a cidade absorver todas as novidades que poderiam servir para sua evolução.

No decorrer da história de Roma podemos notar uma coerência na política de conquistas. Mesmo em relação aos imperadores menos adeptos a essa política, percebemos que há certa coerência quanto às formas de imposição do poderio romano, como no caso de Adriano², conforme tradução de Yourcenar (1980): "Dentro dos limites intransponíveis de que falava ainda há pouco, conto defender minha posição passo a passo e até mesmo reconquistar algumas polegadas de terreno perdido (YOURCENAR, 
1980:14)". A política de conquista de Roma era baseada na romanização dos povos conquistados, ou seja, a tentativa de transformar ao máximo os povos sob seu domínio ao modelo da civilização romana. "Os gregos não cogitavam transformar os povos conquistados em atenienses. Roma, sim, queria exatamente uma metamorfose desse tipo (SENNETT, 1997:87)". Estavam contidas nela o incentivo aos cultos e crenças da religião oficial de Roma, a padronização arquitetônica das cidades e monumentos como réplicas da metrópole e o direito romano.

Iniciada por César, a extensão da cidadania romana aos povos conquistados incluía principalmente a implementação do direito romano. Com isso ficava muito mais fácil para Roma manter o controle do Império. Mesmo com toda a diferença entre os imperadores essa estratégia se manteve ao longo do apogeu de sua expansão territorial.

Apesar de Roma ter conseguido se tornar um dos maiores impérios já vistos na história antiga do ocidente, sua estratégia de domínio e controle territorial não foi capaz de suportar as proporções adquiridas após o período de Trajano. Acreditamos que um importante motivo responsável pelo declínio de Roma deve-se a falta de recursos tecnológicos que possibilitassem aos romanos estarem presentes em toda a extensão do Império com a mesma intensidade, tornando algumas províncias mais vulneráveis a ataques bárbaros e revoltas internas. Os fluxos de informações entre as províncias e a capital não eram rápidos o bastante para conseguir viabilizar políticas homogêneas a todo o Império.

Tendo em vista o período histórico em que Roma foi hegemônica no mundo Ocidental, podemos afirmar que os romanos revolucionaram as táticas de dominação dos povos conquistados por um Império. Sendo assim iremos a seguir especificar entre as políticas de romanização a padronização da arquitetura monumental e o ordenamento territorial das cidades romanas para assim analisá-las enquanto territorialidade do Império Romano.

\section{Ordenamento territorial das cidades romanas.}

Como vimos Roma tinha na padronização da arquitetura monumental e no planejamento de suas cidades importante arma política para a romanização dos povos conquistados. Os romanos buscavam ao máximo reproduzir nas cidades provinciais o modelo de sua capital, construindo réplicas das edificações e distribuindo-as ao longo das cidades como em Roma.

Se, de facto, o poder militar dos povos subjugados por Roma foi quebrantado pelas legiões, foi a cidade 
romana que - pelo menos nas províncias ocidentais assegurou a "romanização" do território conquistado. Os romanos não se deixaram induzir em erro e serviram-se do seu urbanismo como de um poderoso instrumento político (GRIMAL, 2003:10).

Contudo, a fundação de uma cidade romana era cercada de ritos e significados religiosos. $\mathrm{O}$ rito fundador que foi implantado em Roma por Rômulo foi o mesmo utilizado em todas as demais cidades romanas. A fundação de uma cidade era realizada por um magistrado oficialmente preparado para essa missão (geralmente ocupado por um agrimensor). Ele determinava onde ia estabelecer o decumanus maximus - reta que corta a cidade de leste a oeste - de acordo com a posição que o sol nasceu naquele dia. Depois era encontrado o centro dessa reta, localização do mundus ${ }^{3}$, onde se traçava uma outra reta perpendicular à primeira, chamada cardo maximus, orientada de norte a sul. Dessa forma estava pronta a base para a construção da cidade. As portas da cidade localizavam-se nos quatro pontos cardeais e as ruas adjacentes chamadas de decumani e cardines eram traçadas paralelamente aos dois eixos principais, formando um tabuleiro de xadrez (Figura 1). Além disso, era feito um fosso ao redor da cidade, onde mais tarde seria construída uma muralha que a cercaria. Por último construíam-se três capelas em honra aos deuses Júpiter, Juno e Minerva no alto de uma colina (capitólio), objetivando a proteção dos céus (GRIMAL, 2003).

Sabemos que nem toda cidade romana era construída como um tabuleiro, mas devido ao fato da fundação ser antes de tudo um ato religioso, os romanos sempre traçavam o decumanus e o cardo, mesmo que depois mal pudessem ser reconhecidos após o fim da construção da cidade. Dessa forma os romanos tentavam ao máximo reproduzir o modelo de fundação.

Os historiadores antigos afirmam que esse padrão quadricular das cidades romanas é originário dos etruscos, todavia não se sabe ao certo sua origem. Já se tem comprovado a existência de cidades etruscas e gregas com esse mesmo padrão na Península Itálica, mas essas civilizações não tinham em tal padrão uma regra a ser seguida. Mesmo que não tenha sido os romanos a inventarem esse tipo de ordenamento urbano, foram eles que 0 reproduziram com maior intensidade.

(...) nenhuma outra civilização praticou, como os romanos, durante a última República e o Império, a imposição de um padrão urbanístico constante e uniforme nas cidades, na região rural e nos acantonamentos militares, com tanta persistência e quase obsessividade (RYKWERT apud SENNETT, 
1997:100).

$\mathrm{Na}$ verdade existiam dois tipos diferentes de traçado urbanístico das cidades romanas: a cidade "retangular" (Figura 1) e a "quadrada" (Figura 2). A primeira - já mencionada - se refere às cidades construídas em terrenos continentais. A segunda - onde podemos perceber uma forte influência grega (GRIMAL, 2003) - são aquelas fundadas em regiões litorâneas. Nelas o decumanus era paralelo ao litoral e bem mais alongado que o cardo. Esse padrão tinha como principal objetivo favorecer a construção de portos e consequentemente o comércio marítimo.

Figura 1: Planta de Óstia antiga

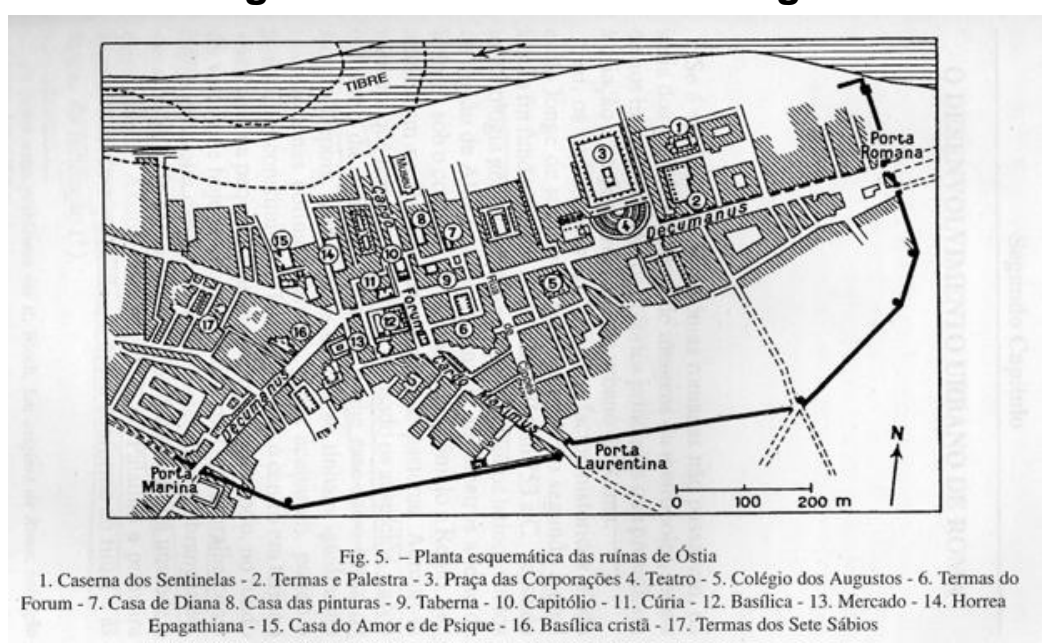

Fonte: GRIMAL, Pierre. As cidades romanas. Lisboa: Edições 70 2003, p.35.

Figura 2: Planta da cidade de Cápua antiga

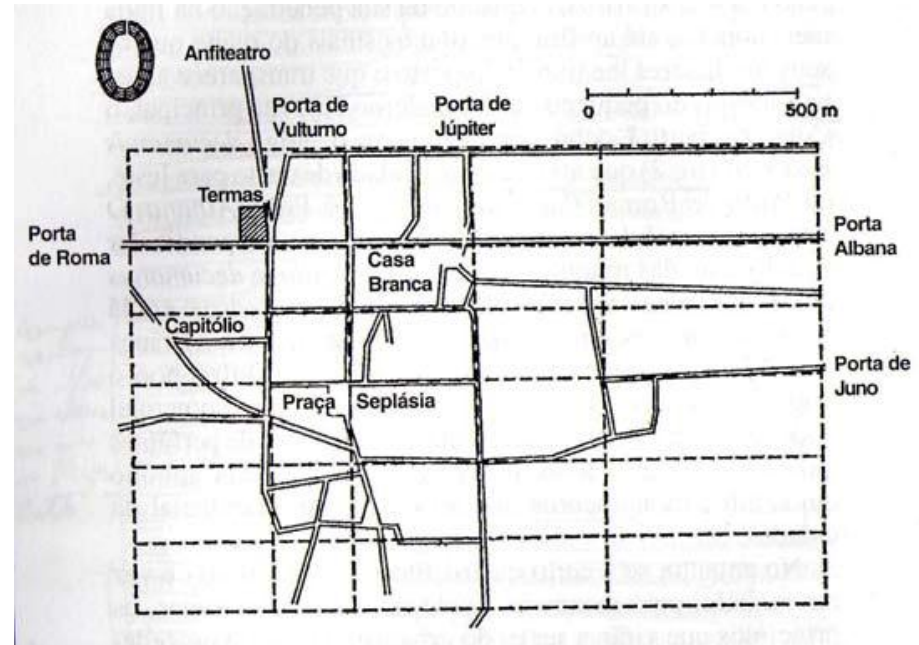

Fig. 2.- Planta de Cápua antiga

A tracejado: traçado teórico das estradas antigas

A traço cheio: traçado das estradas modernas

Segundo J. Heurgon, Capoue préromaine, já citado.

Fonte: GRIMAL, Pierre. As cidades romanas. Lisboa: Edições 70, 2003, p. 26. 
Sabemos que Roma demonstrou uma forte obsessão por figuras geométricas, reproduzindo-as na sua arquitetura. Dessa forma encontramoas sempre presentes em suas construções e monumentos. Assim como no caso das cidades, outras civilizações possuíam essa mesma fixação, tornando difícil identificarmos sua origem em Roma. Entre os arquitetos antigos podemos destacar o romano Vitrúvio como um dos mais importantes adeptos dessa linha. $O$ arquiteto percebeu no corpo humano uma simetria que tempos mais tarde seria representada por Leonardo da Vinci em sua obra "O Homem Vitruviano". Nela o umbigo era considerado o centro do corpo humano e os membros teriam suas extremidades a mesma distância desse centro. Foi a partir dessa percepção que Vitrúvio buscou implantar em todos os seus projetos arquitetônicos essa mesma simetria.

Tanto Vitrúvio quanto outros arquitetos romanos transformaram essa simetria do corpo humano em um padrão seguido ao longo da história romana no planejamento das cidades e nas construções. Sendo assim podemos observá-lo nos monumentos, nas residências e nas demais construções romanas.

Corpo, casa, fórum, cidade, império baseavam-se em imagens lineares. Os críticos da arquitetura mencionam a obsessão romana de organizar o espaço de forma clara e precisa - espaços ortogonais bem definidos, como a rede romana; estruturas rígidas, como o arco romano; prédios rigorosamente desenhados, encimados por domus - simples transferência do semicírculo para o plano tridimensional. Essa linguagem visual, ou desejo de orientação exata, demonstrava a mesma ânsia que se expressava no gosto pela repetição interminável de imagens, até que se convertessem em verdades inquestionáveis. (...) A geometria procurava dar idéia de uma Roma eterna e essencial, que permaneceria de algum modo a salvo das rupturas históricas. Embora dominando essa linguagem, Adriano sabia que ela não passava de ficção (SENNETT, 1997:107).

Roma buscou ao máximo reproduzir as formas geométricas em suas construções, muitas para transpor uma idéia de perfeição e com isso criar na população um sentimento de inferioridade à grandeza do Império. Em alguns casos a fixação pelo padrão linear ocorria por limitação tecnológica, vide a forma como eles construíam suas estradas - onde só se permitiam construir curvas de $90^{\circ}$ - que ligavam os pontos extremos do Império a sua capital.

Como dissemos anteriormente, os romanos tinham na cidade de 
Roma o modelo a ser seguido na construção de novas cidades. Contudo ela não seguia o padrão de uma cidade quadrada - passando a possuir ruas que se cruzam em forma de estrela -, adotado após o rito fundador de cidades. Dessa forma os romanos tentavam reproduzir ao máximo os elementos paisagísticos encontrados na capital e assim levar para as províncias a divisão social existente em sua própria cidade, periferizando os pobres e centralizando os ricos.

\section{A divisão sócio-econômica nas cidades romanas.}

Como sabemos a população romana era dividida entre patrícios e plebeus, sendo os primeiros os cidadãos providos de posses (terras, escravos etc.) e a segunda ocupada pelos menos favorecidos. Durante a história de Roma esses dois grupos estiveram em constante conflito, principalmente no período republicano, onde o senado - que era composto de patrícios buscava sempre o benefício da aristocracia. Essa divisão acabou sendo expressa na própria distribuição dos espaços da cidade.

Durante o período dos Tarquínios, Roma se limitava aos montes Palatino, Capitolino e Aventino. À medida que a população foi crescendo ela se estendeu para os outros montes que juntos originaram o apelido de 'cidade das sete colinas: Quirinal, Viminal, Oppius e Célio; sendo esses prolongamentos do planalto Esquilino.

Os patrícios - por serem descendentes da tribo do Lácio - ocupavam desde os tempos primitivos o monte Palatino. Com o tempo eles também ocuparam o monte Quirinal. Já os plebeus ocupavam o monte Aventino, mas de forma dispersa devido a sua posição pouco central. Com o passar do tempo e o crescimento populacional da cidade, a periferização sócio-espacial em Roma torna-se cada vez mais evidente, centralizando os mais favorecidos e periferizando os desprovidos de posses (GRIMAL, 1987).

Cabe destacar que os patrícios usavam do seu poder econômico objetivando arrebatar um número considerado de plebeus, ajudando-os em trocas de favores que iam desde uma simples compra no mercado até crimes como roubos e assassinatos. Com isso eles agrupavam um grande contingente de desprovidos para servirem como massa de manobra.

À medida que o Império crescia, surgia na capital uma série de grupos que se diferenciavam culturalmente dos romanos, como no caso dos judeus e dos próprios cristãos. Suas crenças - em muitos aspectos contrárias a religião oficial romana - os tornavam alheios ao estilo de vida romano, onde praticamente todas as atividades eram associadas a um tipo de culto pagão.

Nas cidades provinciais essa divisão ganhava uma outra característica. Após uma conquista os romanos buscavam estabelecer sua política de 
romanização, começando pela fundação ou reconstrução da cidade nos seus moldes. Com os edifícios romanos prontos iniciava-se a introdução do seu modo de vida e os cargos políticos eram ocupados pelos romanos. No entanto, entre a população conquistada já existia uma divisão entre a oligarquia local e os desprovidos e com o tempo os primeiros começavam a buscar um lugar na vida política da nova cidade. Para tanto era necessário que se fizessem alianças com os romanos instalados na província, numa postura contrária à massa desfavorecida que ainda sofria com as mudanças no modo de vida.

Dessa forma podemos identificar nas cidades provinciais uma divisão entre os oligarcas locais e os romanos, sendo que os segundos detinham o controle da província até que as políticas de romanização obtivessem o sucesso desejado. Como nem sempre os romanos eram bem sucedidos muitas vezes era necessário um controle mais efetivo da província, limitando o papel da oligarquia local, como no caso das províncias britânicas que durante todo o tempo de ocupação romana não se renderam às políticas de romanização, principalmente na região norte, o que obrigou o imperador Adriano a construir uma muralha para conter os constantes ataques dos povos que lá viviam (MONTEIRO, 1963).

Numa cidade em que a romanização foi consolidada a divisão social era bem próxima da existente na capital do Império, salve as particularidades de cada província. Os romanos buscavam exercer sua vontade tentando deixar a impressão de que a romanização era um favor oferecido aos povos conquistados e assim tinha-se o cuidado de não parecer estar impondo-a.

Como vimos anteriormente, a capital do Império servia como inspiração para as cidades fundadas ou reconstruídas, contudo nem sempre isso era possível, principalmente devido às diferenças na topografia. Mesmo assim, os romanos tentavam pelo menos reproduzir seus edifícios mais importantes, com o objetivo de levar o estilo de vida romano para os povos conquistados.

A lenda que cerca a história da fundação de Roma menciona a existência de uma 'cidade quadrada' originária do ritual realizado por Rômulo. Todavia não se encontrou nenhum vestígio dela nas escavações arqueológicas. Sabemos, no entanto, que o primeiro Fórum romano localizase na planície entre os montes Palatino e Capitolino. Os Fóruns que foram sendo construídos com o passar do tempo continuavam nessa localidade e toda cidade cresceu no seu entorno. A importância atribuída ao Fórum na sociedade romana é oriunda do grande número de atividades que abrigava, indo desde assembléias e atos públicos, até as atividades comerciais mais importantes (GRIMAL, 2003).

Como podemos perceber os romanos gostavam de centralizar as atividades mais importantes, o que justifica o fato do Fórum sempre estar no centro de uma cidade romana. Contudo, o crescimento da cidade se deu "(...) sem que se pudesse discernir um plano bem definido (GRIMAL, 2003:43)". 
Apesar das tentativas da Roma republicana crescer em volta do Fórum, não foi respeitado o plano estabelecido pela "cidade quadrada", fato que apagou os antigos decumanus e cardos, desenhando-se no antigo cruzamento perpendicular num plano em estrela. $O$ crescimento das atividades econômicas e políticas - além do crescimento populacional - trouxeram a Roma sérios problemas de ordem urbana que atormentaram todo periodo republicano.

O problema principal que então se passa a pôr aos Romanos é menos o de construir edifícios públicos do que $o$ de encontrar espaços livres. Roma tinha permanecido uma pequena cidade ao mesmo tempo que se tornava capital de um imenso Império. O número dos seus cidadãos tinha crescido desmensuradamente mas os instrumentos da vida pública continuavam ainda, no fim da República, a ser aquilo que eram dois séculos antes (GRIMAL, 2003:46).

A partir da vitória de César e dos posteriores imperadores, a cidade conseguiu destinar políticas objetivando solucionar tais problemas. Nesse período Roma estava fervilhando de recursos vindos dos despojos das conquistas e os imperadores investiram massiçamente na transformação de sua capital. Podemos notar uma clara competição existente no período imperial na qual um imperador tentava superar seus antecessores na grandiosidade de suas construções. Com isso de governo a governo iam surgindo novas cidades, monumentos, templos, fóruns, termas, basílicas, entre outras construções importantes para os romanos. Todos na tentativa de enaltecer a grandeza do Império Romano e na idéia de uma capital eterna, transformando Roma em um constante canteiro de obras. Cabe destacar que a arquitetura monumental é utilizada até hoje como uma forma de sedução e uma tentativa de esconder os problemas sociais existentes numa cidade.

Como vimos a capital do Império Romano tinha em sua paisagem elementos construídos que ditavam as diretrizes da civilização romana. Quando junto ao restante do pacote de políticas de romanização, representava a legitimação do domínio romano. Dessa forma iremos a seguir propor a articulação entre os conceitos de território e territorialidade aos de romanização e a política de conquistas. 


\section{As territorialidades expressas na política de conquistas}

A territorialidade corresponde às táticas expressas em ações aplicadas por indivíduos sobre um determinado grupo objetivando seu controle. As ações materializam as relações de poder exercidas no espaço, conformando assim um território. Numa visão integradora ${ }^{5}$ elas irão interagir umas com as outras e cada territorialidade influenciará as demais, tanto nas escalas macro quanto micro. Consideraremos com isso que um território pode ser concebido sobre muitas escalas espaciais e temporais.

No decorrer da evolução social podemos perceber o aparecimento de territorialidades antes inconcebíveis graças ao advento de aparatos tecnológicos que os possibilitaram. Contudo não podemos negar que a existência de múltiplas territorialidades sempre ocorreu na história da humanidade, de forma menos intensa e com escalas temporais mais prolongadas, mas sem deixarem de estar sobrepostas e integradas.

O Império Romano exercia sua territorialidade determinando os cultos, as leis, os entretenimentos entre outros aspectos de sua cultura e organização sócio-espacial. Contudo foi na padronização de sua arquitetura e nas construções que eles conseguiam os melhores resultados quanto ao domínio da massa. "A geometria do espaço romano disciplinava o movimento corporal e, nesse sentido, conduzia à regra de olhar e obedecer, intrinsecamente vinculada ao diktat olhar e acreditar (SENNETT, 1997:102)".

A população romana vivia sobre constante opressão, com a maior parte dos imperadores privilegiando as classes mais favorecidas, além de conviverem com as loucuras e abusos de poder desses. A grande quantidade de obras era executada a custa de muita mão-de-obra escrava, que apesar da exploração aceitavam sua condição sem que muitos casos de rebeliões tenham sido relatados ${ }^{6}$. Já os indivíduos pobres e livres se deixavam levar pela sedução dos grandes monumentos e do endeusamento dos imperadores. Cabe destacar que em Roma a religião misturava a crença em deuses místicos com o culto a pessoas divinizadas, como no caso da religião familiar onde se cultuava geralmente um patriarca ou alguém importante da família. Mas o culto à cidade sem dúvida era a territorialidade mais eficiente do Império.

A capacidade de construir monumentos e edifícios gigantescos como o Pantheon e o Coliseu são comparados com o poder exercido pelo avanço tecnológico de hoje. Se nos dias atuais a tecnologia dita o ritmo de vida das pessoas, o mesmo ocorria no período do Império Romano, a diferença está no tipo de tecnologia. Roma desenvolveu uma eficiência em construção só alcançada no período dos estados modernos com o advento da computação e pouco se sabe hoje sobre as técnicas de construção dos romanos.

Os romanos exerciam sua territorialidade através da força, ou melhor, 
pelo culto ao medo tanto em termos concretos (o medo de sofrer violência) quanto abstratos (de cunho religioso). Toda cidade romana era planejada com o objetivo de embutir o medo e a devoção na população e dessa forma conformar o domínio territorial. As construções ditavam o cotidiano dos indivíduos, com os horários para os cultos, para os banhos etc.

Geralmente os monumentos eram orlados por desenhos em alto relevo ou mosaicos contando histórias dos êxitos de Roma. Isso servia como propaganda imperial. Vide que vários imperadores construíram colunas, estátuas, entre outros monumentos de auto-promoção. Além disso, os romanos tinham obsessão em planejar suas cidades de forma prática e ao mesmo tempo eficiente, buscando sempre um deslocamento para frente, sem que existam outros elementos que chamem a atenção lateralmente (SENNETT, 1997).

(...) Em 318, sobre um aglomerado de lojas perto do fórum, construiu-se um segundo pavimento mais comprido (Maeniana), onde se expunham em ordem cronológica os suvenires das conquistas do império. Andando por essa "espinha", o visitante poderia acompanhar a história do poder que Roma acumulara nas guerras (SENNETT, 1997:101).

Dessa Roma era o modelo a ser seguido na fundação de novas cidades, forma os romanos conseguiam reproduzir todo o cotidiano de sua capital nas demais cidades a partir do estilo implantado em suas edificações. Essa tática estava contida na estratégia de romanização, na qual incluíam a expansão da cidadania romana, a introdução dos cultos, entre outros. Entendemos que cada uma dessas táticas corresponde às territorialidades exercidas pelo Estado romano para obter o domínio territorial. Dessa forma a romanização seria o conjunto de territorialidades do Império. A unidade do Império era composta por essas táticas que se formos analisar a luz da História foram bem sucedidas, visto que o Império conseguiu manter boa parte de sua extensão territorial por vários séculos.

Vários povos da época possuíam essa mesma ânsia de conquistas, mas nenhum teve a intenção de transformar de forma tão incisiva o modo de vida dos povos conquistados quanto Roma. Hoje estamos vivendo num período em que o processo de globalização vem se intensificando pelo avanço da tecnologia, conectando redes por todo o mundo, todavia esse fenômeno é dominado pelos interesses capitalistas, onde não se preocupam com as dificuldades das economias de países frágeis, criando uma massa de excluídos. Se compararmos com o período romano, percebemos que as políticas de romanização se encontram bem próximas dessa atual globalização, visto que ambas atingem os laços culturais do indivíduo com 
suas origens. O domínio do meio técnico-científico-informacional norteia o ritmo de vida da população, pois cria um sentimento de dependência a partir da sedução desenvolvida pelos meios de comunicação de massa. Se em Roma o domínio de técnicas de construção era utilizado como importante tática de romanização, hoje as técnicas de propaganda e fluxos informacionais são um dos principais meios de alienação utilizados (SANTOS, 2004).

Roma exercia sua territorialidade a partir do domínio de técnicas e táticas que postas em ação determinavam as políticas de romanização. Sendo assim iremos analisar o processo de romanização das cidades provinciais, entendendo-as enquanto as ações implantadas nos territórios recém conquistados para estabelecerem o domínio romano. Com isso acreditamos que o trabalho pode ajudar a Geografia a melhor entender 0 seu papel no cenário acadêmico, entendendo que não devemos estimular uma visão fragmentada e isolacionista das ciências, pois a evolução do pensamento geográfico sempre foi pautada no dialogo entre diversas ciências.

\section{Notas}

1- Guerra promovida em meados dos séculos III e II a.C. entre Cartago e Roma, onde disputavam principalmente o controle do Mar Mediterrâneo (GRIMAL, 1984).

2- Imperador romano que governou nochamado período antonino entre os anos de 117 e 138, tendo como antecessor o Imperador Trajano e como sucessor Marco Aurélio. (BOWDER, 1980).

3- Fosso que determinava o centro da cidade e onde os romanos enterravam oferendas aos deuses de 'baixo' (SENNETT,1997).

4- Leonardo da Vinci coloca um homem dentro de um círculo e um quadrado, mostrando dessa forma a simetria identificada por Vitrúvio.

5- Deste modo, a existência do que estamos denominando multiterritorialidade, pelo menos no sentido de experimentar vários territórios ao mesmo tempo e de, a partir daí, formular uma territorialização efetivamente múltipla, não é exatamente uma novidade, pelo simples fato de que, se o processo de territorialização parte do nível individual ou de pequenos grupos, toda relação social implica uma interação territorial, um entrecruzamento de diferentes territórios (HAESBAERT, 2004:344). 
6- Um dos poucos casos de revolta escrava foi a de Espartacus, escravo que liderou uma rebelião já no final do período republicano.

\section{Bibliografia}

ABREU, Maurício de Almeida. "A apropriação do território no Brasil Colônia". In: CORREA, CASTRO e GOMES (orgs.). Explorações Geográficas. Rio de Janeiro: Bertrand Brasil, 1997.

BOWDER, Diana. Quem foi quem na Roma Antiga. São Paulo: Art. Editora LTDA. 1980.

BRAUDEL, Fernand. O espaço e a história no mediterrâneo. Rio de Janeiro: Martins Fontes, 1985.

CORREA, Roberto Lobato. "Espaço: um conceito-chave da Geografia" In: CORREA, CASTRO e GOMES (orgs.). Geografia Conceitos e Temas. Rio de Janeiro: Bertrand Brasil, 2003.

COSTA, Benhur Pinos. "As relações entre os conceitos de território, identidade e cultura no espaço urbano: Por uma abordagem Microgeográfica" in: ROSENDAHL, Zeny \& CORREAA, Roberto Lobato (orgs.). Geografia: Temas sobre cultura e espaço. Rio de Janeiro: EdUERJ, 2005.

DESLANDES, Suely Ferreira. "A construção do projeto de pesquisa" in: MINAYO (org.). Pesquisa e criatividade. Petrópoles: Ed. Vozes, 1994.

GONÇALVES, C. W. "Da Geografia às Geo-grafias: Um mundo em busca de novas territorialidades" in: SADER, CECEÑA (orgs.). La guerra infinita: hegemonía y terror mundial. Buenos Aires: CLACSO, 2002.

GRIMAL, Pierre. A Civilização Romana. Lisboa: Edições 70, 1984.

O Império Romano. Lisboa: Edições 70, 1993.

As Cidades Romanas. Lisboa: Edições 70, 2003.

HADAS, Moses. Roma Imperial. Rio de Janeiro: Livraria José Olympio Editora S.A., 1969.

HAESBAERT, Rogério. "Concepções de Território para Entender a Desterritorialização” in: Programa de Pós-Graduação em Geografia. Território 
Territórios. Niterói: PPGEO-UFF/AGB-Niterói, 2002.

- O Mito da desterritorialização: do "fim dos territórios" à multiterritorialidade. Rio de Janeiro: Bertrand Brasil, 2004.

LEPETIT, Bernard. "Sobre a escala na história" in: REVEL, J. (org). Jogos de Escalas: a experiência da microanálise. Rio de Janeiro: FGV, 1999.

LESSA, Ana. Atlas da história mundial. Rio de Janeiro: Reader's Digest Brasil, 2001.

MONTEIRO, Domingos. O livro de todos os tempos: Roma e a Civilização. Rio de Janeiro: Ed. Lidador LTDA, 1963.

MORAES, António Carlos Robert. Território e História no Brasil. São Paulo: Annablume, 2005.

RAFFESTIN, Claude. "O que é território". In: Por uma Geografia do Poder. São Paulo: Ed. Ática, 1993.

RIBEIRO, Guilherme da Silva. "Epistemologias Braudelianas: Espaço, Tempo e Sociedade na construção da Geo-História”. In: GEOgraphia. Niterói: UFF, v. 16, p. 87-114, 2007.

RIBEIRO, Miguel (org.) Território e Prostituição na Metrópole Carioca. Rio de Janeiro: Ed. Ecomuseu Fluminense, 2002.

SENNETT, Richard. Carne e Pedra: O corpo e a cidade na civilização ocidental. Rio de Janeiro: Editora Record, 1997.

SILVA, Jan Carlos. 2002. "O conceito de território na geografia e a territorialidade da prostituição”. In: RIBEIRO, Miguel (org.). Território e Prostituição na Metrópole Carioca. Rio de Janeiro, Ed. Ecomuseu Fluminense.

SOUZA, Marcelo Lopes de. "O território: sobre espaço e poder, autonomia e desenvolvimento". In: CORREA, CASTRO e GOMES (orgs.). Geografia Conceitos e Temas. Rio de Janeiro: Bertrand Brasil, 2003.

VANDENBERG, Philipp. Nero. São Paulo: Editora Círculo de Livro, 1981.

YOURCENAR, Marguerite. Memórias de Adriano. Rio de Janeiro: Nova Fronteira, 1980. 